\title{
Medical Humanities in Nepal: Present Scenario
}

\author{
Ajaya Kumar Dhakal, ' P. Ravi Shankar, ${ }^{2}$ Sanjaya Dhakal, ${ }^{3}$ Devendra Shrestha, ${ }^{1}$ Rano Mal Piryani ${ }^{4}$ \\ 'Department of Pediatrics, KIST Medical College, Lalitpur, Nepal, ${ }^{2}$ Department of Pharmacology, Xavier University School of \\ Medicine, Aruba, Dutch Caribbean, 3 School of Public Health, University of Alberta, ${ }^{4}$ Department of Medicine, KIST Medical \\ College, Lalitpur, Nepal.
}

\section{ABSTRACT}

Humanities have an essential role in medical education. The current gap between the humanities and medicine has to be bridged and there should be continuous and vigorous debate about the theory and practice of medical humanities. Medical humanities is a relatively new concept even in developed countries, and is at infancy stage in developing countries. In Nepal, modules on medical humanities have been initiated in certain medical schools by enthusiastic faculties and it requires further debates for inclusion in curriculum.

Keywords: humanities; medical education; medical humanities.

\section{INTRODUCTION}

Medical humanities as defined by Kirklin, is an 'interdisciplinary, and increasingly international endeavour that draws on the creative and intellectual strengths of diverse disciplines, including literature, art, creative writing, drama, film, music, philosophy, ethical decision making, anthropology and history in the pursuit of medical educational goals' 1

Medicine has passed through stages where patients were treated with herbal medicine, faith healing and supernatural beliefs to the modern era, largely dominated by medical technology. Medical humanities bridges medical technological innovations with humanistic knowledge. ${ }^{2}$ Medical humanities is a new concept in medical education and is crucial in understanding the link between human health and disease, which influences approach to a patient and implementation of healthy health policy. This vision initiated huge interest in medical humanities in United Kingdom and the United States in last few decades. ${ }^{2}$ This has resulted in creation of speciality journals, ${ }^{2}$ and inclusion of medical humanities as a distinct discipline in both undergraduate and postgraduate education. ${ }^{3}$

This article highlights the current situation of medical humanities in Nepal and efforts of few medical schools in conducting medical humanities sessions for medical students.

\section{OBJECTIVES OF MEDICAL HUMANITIES}

The two main objectives of medical humanities as stated by Greaves and other are 'integration of medical science and technology with arts and humanities but without imposing each other and to refocus the medical education in relation to the understanding of what it is to be fully human'.2 
Medical education concentrates on providing the current medical information; opportunities for generation of new medical knowledge without losing the basic human values and ethics of medicine, the foundation of which was laid centuries ago. Medical education aims to produce dedicated, humane, empathetic and knowledgeable future physicians who are true medical leaders of the society with broader cognizance of humanity. ${ }^{4}$

Medical students today, because of poor training, burden of work and study, unrealistic expectations, fear of examinations and stress of alarmingly expensive medical education, are becoming less empathetic, and more distanced from their patients. Overall the patientcentred care gets affected by the prevailing stress and frustration. Jones and Carson stated 'medical humanities contribute to the education of physicians by encouraging intellectual and professional growth, the cultivation of sound judgment, and the enlargement of character, virtues and skills indispensable to good doctoring' ${ }^{3}$

Medical humanities sessions involve teaching medical students a regular academic course along with combination of literature written by physicians and patients about disease, experiences of illness from doctors and patients perspective, painting or photographic exhibits of sickness and disease, musical performance, drama, dances, role play, poetry etc related to medicine that will help to learn medicine. ${ }^{5}$

\section{MEDICAL HUMANITIES MODULES AND WORKSHOPS IN NEPAL}

Humanities in medical education is at infancy stage and growing slowly in Nepal and discussions are ongoing to include the subject in the medical curriculum to produce a 'global physician'.6

The first medical humanities module for Nepalese medical students was developed and conducted by a group of faculties in $\mathbf{2 0 0 7}$ for interested third, fifth and sixth semester MBBS students and faculty members at the Manipal College of Medical Sciences, a private medical college at Pokhara, affiliated with Kathmandu University. ${ }^{7}$ Small-group interactive sessions, literature, art excerpts, case scenarios, role-plays and debates were used. Sessions focussed mainly on medicine and the arts, ethics and medicine, and social issues in medicine. Feedback, which was obtained using focusgroup discussions and reflective writing assignments, found that medical students had a receptive attitude towards the medical humanities, ${ }^{7}$ and a suggestion of inclusion of medical humanities in the curriculum of Kathmandu University (one of the private universities in the country to which many medical schools are affiliated) as a voluntary module was made. ${ }^{8}$ Even though students found these sessions interesting and beneficial for future practice, it was a huge task to keep the motivation and maintaining sustainable interest among students. ${ }^{7}$

The sessions were later extended to KIST Medical College (a private medical college at Lalitpur, affiliated with Tribhuvan University) as a part of teaching and learning activities. Medical humanities sessions were initially conducted in 2008 among faculties of KIST Medical College using literature excerpts, paintings, case scenarios, small group work and role plays. ${ }^{9}$ These sessions concentrated on empathy, the patient, the family, the caregiver, the doctor-patient relationship, breaking bad news and euthanasia, obtaining informed consent, abortion, patient participation in clinical research, dealing with the HIV-positive patient, dealing with the mentally ill, and women and medicine. Based on the positive feedback from participants, ${ }^{9}$ and with a few modifications, sessions covering empathy, the doctor patient relationship, the caregiver, the family, dealing with HIV-positive patients, the medical student, and what it means to be sick in Nepal were introduced and conducted to the first year medical students at November 2008. These sessions were of one and half hours in length and delivered once a week. Facilitators played an important role during short presentations, providing input during discussion of case scenarios, paintings, literature excerpts and role plays in a friendly environment. ${ }^{10}$

These sessions have been regularly conducted at KIST Medical College over the last five years starting from 2008. There are different activities used in these modules, among them were small group activities, paintings, case scenarios, role plays, debates, literature excerpts, reflective writing assignments, and an online medical humanities group and these activities are helping students to learn effectively different aspects medicine in relation with humanities. Medical humanities have been beneficial to students and they feel that the module offered a positive approach to medicine and help them to learn in enjoyable manner and believe that it will be useful in their future medical practice. ${ }^{11}$ There were even workshops organized in collaboration with College of Medical Sciences (a private medical college at Bharatpur, affiliated with Kathmandu University) to create awareness on medical humanities. ${ }^{12}$ These kinds of regular meetings and workshops among clinical and nonclinical medical educators regarding medical humanities will reduce apprehension and friction among educators. ${ }^{13}$ At the same time, there is a huge challenge to sustain medical humanities programme on a voluntary basis due to lack of resources, creating and 
sustaining interest of faculties and shortage of trained human resources. ${ }^{11}$

\section{MEDICAL HUMANITIES IN OTHER COUNTRIES}

Medical humanities programs are common in developed countries like the United States, United Kingdom, Canada, Australia and New Zealand. ${ }^{14}$ These modules are offered in most medical schools in United States. In the United States, notable examples of institutions offering medical humanities programs are University of Rochester School of Medicine and Dentistry, North Eastern Ohio University College of Medicine, Stony Brook University School of Medicine, and University of California, Irvine College of Medicine. ${ }^{14}$ Courses are offered during different years of undergraduate study using various learning modalities like literature, paintings, sculpture, drama and theatre to explore various aspects of the subject. ${ }^{14}$ Most medical humanities programs in Canada are offered as electives but also as an nonelective programs by few medical schools. There are multiple approaches to teaching medical humanities in Canada like using photography contests, writing contests and retreats etc. ${ }^{14}$

The issue of introducing medical humanities in the undergraduate medical curriculum in India is also being discussed. ${ }^{15}$ At the University College of Medical Sciences in New Delhi, India, various initiatives to promote medical humanities have been carried out during the last three to four years. ${ }^{16}$ Medical humanities was also recently introduced in medical curriculum of Saudi Arabia in 2012 using modules based on history of medicine during the Islamic era, Islamic medical ethics and medically relevant Arabic poetry and followed by feedback. ${ }^{17}$

\section{RELATIONSHIP BETWEEN ETHICS, COMMUNICATION SKILLS AND MEDICAL HUMANITIES}

It has been argued that six framework features unite medical humanities and medical ethics into one distinct field. Among these are both work in a systematic manner using interdisciplinary approaches on certain aspects of the human condition, employ problem solving approaches and find morally justifiable approaches to problems. ${ }^{18}$ However other schools of thought suggest that the bioethics and medical humanities are disciplines with distinct methods of approaching to a problem. Bioethics developed into subject governed by rules with scientific reasoning while medical humanities developed 'humanistic' approach to problem. ${ }^{19}$ During medical humanities modules at KIST Medical College, certain ethical dilemmas and problems like maintaining confidentiality of patient information; ethical implications of changes in the doctor-patient relationship, euthanasia were addressed. The issue of withholding medical treatment and ethical issues concerned with abortion were also covered.

World Health Organization Regional Office for SouthEast Asia has developed a facilitator's guide for teaching medical ethics to undergraduate medical students. ${ }^{20}$ The handbook provides an outline and case scenarios regarding ethics and exercises to facilitators. In Nepal, as modules on communication skills and ethics already exist in the medical curriculum some of these case scenarios and learning methods can also be used to introduce medical humanities without overburdening students.

\section{REGARDING INCORPORATION OF MEDICAL HUMANITIES IN THE CURRICULUM}

A focused and meaningful integration of medical humanities in to basic and clinical sciences curricula not only generate and maintain interest of the medical students but also develop professionalism and medical competencies. However medical humanities are not free from criticism for its content relevancy, teaching method and placement in curriculum. ${ }^{13}$

Tribhuvan University and Kathmandu University, which are among pioneers in medical education in Nepal, had recently introduced communication skills, basic clinical skills lab, medical ethics and information technology modules in the undergraduate curriculum. The medical curriculum of Tribhuvan University recommends teaching communication skills during the first phase of the MBBS curriculum during the first and second year and medical ethics during the third phase. ${ }^{21}$ The current medical curriculum in Nepal has a tight schedule for incorporation of additional modules or courses. However, the authors are hopeful that the medical humanities will be incorporated in the medical curriculum in near future with acknowledgement of its importance in modern day medical education.

The curricula of Nepalese universities stresses on early clinical exposure and medical humanities can be introduced right from the first year as a voluntary module. An additional module can also be offered during the third year developing from the module offered during the first year. It has been recommended that accrediting bodies and universities should provide broad guidelines and the finer details of the module and organization of the course should be left to the faculty in individual schools. ${ }^{11}$ The authors recommends that humanities modules should be based on local resources rather than simply adapting modules from west and should be revised from time to time to encompass new 
issues in medicine and relevant contextual research on medical humanities.

\section{CONCLUSIONS}

Application of humanities in medicine is a new idea in medical education, and there should be discussion around the theory and practice of medical humanities in relation to modern medicine. Students should have the ability to interact effectively with patients and their families. We cannot just treat their illness and should be equally obliged to understand them, their fears and feelings. Sustaining medical humanities programs could be a challenge from lack of resources, motivation and interest of faculties, and shortage of trained human resources. We have to generate new ideas to move this program forward.

\section{ACKNOWLEDGEMENTS}

We acknowledge all students and faculties who participated in the modules facilitated by the authors.

\section{REFERENCES}

1. Kirklin D. The Centre for Medical Humanities, Royal Free and University College Medical School, London, England. Acad Med. 2003 Oct;78(10):1048-53.

2. Greaves D, Evans M. Medical humanities. Med Humanit. 2000 Jun;26(1):1-2.

3. Jones AH, Carson RA. Medical Humanities at the University of Texas Medical Branch at Galveston. Acad Med. 2003 Oct;78(10):1006-9.

4. Finlay SE, Fawzy M. Becoming a doctor. Med Humanit. 2001 Dec;27(2):90-2.

5. Batistatou A, Doulis EA, Tiniakos D, Anogiannaki A, Charalabopoulos K. The introduction of medical humanities in the undergraduate curriculum of Greek medical schools: challenge and necessity. Hippokratia. 2010 Oct;14(4):241-3.

6. Adhikari RK. Humanities in education of doctors. Kathmandu Univ Med J (KUMJ). 2007 Oct-Dec;5(4):443-4.

7. Shankar PR. A voluntary medical humanities module in a medical college in Western Nepal: participant feedback. Teach Learn Med. 2009 Jul;21(3):248-53.

8. Shankar PR. A need to develop medical humanities in Nepal. Kathmandu Univ Med J (KUMJ). 2008 Jan-Mar;6(1):146-7.

9. Shankar PR, Piryani RM, Karki BMS. A medical humanities module for the faculty members of the KIST Medical College, Imadol, Lalitpur. Journal of Clinical and Diagnostic Research. 2011 Nov;5(7):1489-92.

10. Shankar PR, Piryani RM, Thapa TP, Karki BMS. Our experiences with 'sparshanam', a medical humanities module for medical students at KIST Medical College, Nepal. Journal of Clinical and Diagnostic Research. 2010 Feb;4(1):2158-62.

11. Shankar PR. Developing and sustaining a medical humanities program at KIST Medical College, Nepal. Indian J Med Ethics. 2013 Jan-Mar;10(1):51-3.

12. Shankar PR, Subish P, Paudel R. Knowledge and perception about the Medical Humanities before and after a national workshop. Journal of College of Medical Sciences-Nepal. 2011;7(2):72-9.
13. Shapiro J, Coulehan J, Wear D, Montello M. Medical humanities and their discontents: definitions, critiques, and implications. Acad Med. 2009 Feb;84(2):192-8. PubMed PMID: 19174663.

14. Shankar PR. Medical Humanities. In: Biswas R, Martin CM, editors. User-driven healthcare and narrative medicine: utilizing collaborative social networks and technologies. Hershey (PA): Medical Information Science Reference ( IGI Global); 2011. p. 210-27.

15. Ramaswamy R.Embracing theunknown:introducingmedical humanities into the undergraduate medical curriculum in India. Indian J Med Ethics. 2012 Jul-Sep;9(3):174-6.

16. Singh N. Whither medical humanities? Indian J Med Ethics. 2012 Jul-Sep;9(3):166-9.

17. Abdel-Halim RE, Alkattan KM. Introducing medical humanities in the medical curriculum in Saudi Arabia: A pedagogical experiment. Urol Ann. 2012 May;4(2):73-9.

18. Kopelman LM. Bioethics and humanities: what makes us one field? J Med Philos. 1998 Jun;23(4):356-68.

19. Friedman LD. The precarious position of the medical humanities in the medical school curriculum. Acad Med. 2002 Apr;77(4):320-2.

20. World Health Organization South-East Regional Office. Facilitators' Guide for teaching medical ethics to undergraduate students in medical colleges in the South-East Asia Region [Online]. 2010 [cited 2013 Sep 7]; Available from: URL: http://apps.searo.who.int/pds_docs/B4477.pdf.

21. Tribhuvan University Institute of Medicine. Curriculum for Bacheolr of Medicine and Bacheolr of Surgery (MBBS). Amendments made in the MBBS curriculum (2008). Maharajgung, Kathmandu, Nepal: Medical Education Department; 2008. 